\title{
PROMOTING STAKEHOLDER COLLABORATION IN ADOPTING CIRCULAR ECONOMY PRINCIPLES FOR SUSTAINABLE CONSTRUCTION
}

\author{
Sepani Senaratne ${ }^{1}$, Abhishek KC ${ }^{2}$, Srinath Perera $^{3}$ and Laura Almeida ${ }^{4}$
}

\begin{abstract}
Circular Economy (CE) has been recognised as one of the most comprehensive way of attaining sustainable development, which considers every aspect; social, technical, economic and environmental, of sustainable development. For a building construction project that aims to achieve circularity, collaboration of project stakeholders both within vertical horizontal supply chains is vital. This research project establishes importance of such collaboration and proposes methodology to identify stakeholders responsible for attaining circularity in projects through collaboration between such stakeholders. This paper reports of the key literature findings of this on-going research. The key findings from the current paper are establishing importance of stakeholder collaborations to achieve circular buildings and potential of blockchain technology in this regard.
\end{abstract}

Keywords: Blockchain; Circular economy; Sustainable construction; Stakeholder management.

\section{INTRODUCTION}

The industrial production till now has been mostly in linear model i.e., of take, make and dispose of resources, which has given an extraordinary growth but it has come with significant wastage in terms of resources and other negative externalities in environment as by-products. EMF (2012) has defined circular economy as restorative and regenerative process, where the utility of any product, resources is optimised and used to its highest value and 'end of life' is replaced with restoration, while adapting renewable energy sources during the process. It is the process of designing out waste through its biological and technical cycles, while maintaining certain economical value at every stage of cycle (EMF, 2015). In other words, the resources loop in circular economy are closed in order to minimise waste through reuse and recycle. Also, using optimum amount of resources

\footnotetext{
${ }^{1}$ Centre for Smart Modern Construction, Western Sydney University, Australia,

S.Senaratne@westernsydney.edu.au

${ }^{2}$ Centre for Smart Modern Construction, Western Sydney University, Australia, 19843009@student.westernsydney.edu.au

${ }^{3}$ Centre for Smart Modern Construction, Western Sydney University, Australia, Srinath.Perera@westernsydney.edu.au

${ }^{4}$ Centre for Smart Modern Construction, Western Sydney University, Australia,

L.Almeida@westernsydney.edu.au
} 
in the production process is termed as 'narrowing the loop' and designing long lasting reusable products is termed as 'slowing the loop' (Bocken et al., 2016).

While the focus of circular economy (CE) is to minimise resources input and waste out of industrial system, its adaption in construction industry seems very important. The construction sector utilises significant amount of resources, accounting to $40 \%$ of materials consumed in global economy (Leising et al., 2018). Whereas, only $20 \%-30 \%$ of the materials are reused or recycled at the end of life of buildings (EMF, 2014; Leising, et al., 2018). It should be noticed that the adapting the complete reuse concept is practically unachievable as there is end of life on various productions using materials, which better be demolished than reused, not to exclude buildings, which typically having 50-70 years of functional lifespan, but most of them are demolished within 20-30 years as they do not meet the users need (Munaro et al., 2020). Current scenario, thus, suggests the importance of $\mathrm{CE}$ in construction.

CE adaption in construction industry comes with its own complications. In case of medium lived products, the materials after repeated maintenance and reuse to possible extent or 'end of life' are taken back by the manufacturer for recycling, but in case of constructed buildings it is tough due to longer life cycle and lower salvage value (Adams et al., 2017). Currently, CE in construction is about recycling construction and demolition waste, but the adaption of $\mathrm{CE}$ in real terms would be from reuse of the materials and resources, which requires the attention from design phase. Buildings should be designed in such a way that its reusability and value is preserved till end of life (Adams et al., 2017). In addition to that, for making a close, narrow and slow loop of materials flow of any building, requires the integration of material supply chain to whole of life cycle of building, where every actor has responsibilities towards circularity (Leising et al., 2018). In other words, the construction value chain has to be integrated into the life cycle of building through circular business models, so that closed loop can be attained and every actor makes some gains during the process and sustain the economy (Hossain et al., 2020; Munaro et al., 2020). To follow and execute these processes requires collaboration between all the stakeholders involved during life cycle of the project such as designers, manufacturers, contractors, demolition companies and recycling companies (Leising et al., 2018). Achieving collaboration among these stakeholders thus can be considered key for adaption of $\mathrm{CE}$ in construction.

Looking into the issues regarding collaboration studied by Adams et al. (2017) with stakeholders in UK, provides industry insights about lack of awareness among the stakeholders regarding circular economy (CE), including clients who should be leaders in this process. Study found that, subcontractors were less aware than others and demolishers mentioned that designers do not practice design for reuse concept. The study, in addition to raising awareness, suggests developing a strong financial case for reuse through collaboration of stakeholders, where parties less benefited in process such as designers could be motivated through financial incentives. Similar suggestions have been made by Hossain et al. (2020) for sustainable business model innovation with circular value chains evolving around stakeholder collaboration. Hence how to achieve collaboration among stakeholders for a close, narrow and slow loop of CE remains the main research question. This paper aims to first understand the circular economy concepts and thereby, highlight the importance of stakeholder collaboration in circular economy adaption for sustainable construction through a literature survey. 


\section{CIRCULAR ECONOMY CONCEPTS FOR SUSTAINABLE CONSTRUCTION}

As the name suggests, circular economy is the economy, where materials, products and energy are intended to flow in a circular path and make a closed loop, which is very different approach than of current linear economy of "take, make and dispose". In linear economy, resources are extracted, products are manufactured and disposed after use at the end of product life. Whereas, in circular economy the practice would be to keep off from disposing, through reuse, remanufacture and recycle. The key objective behind circular economy is to minimise the virgin resource extraction. The current ideas of circular economy have been derived from various ideas in previous decades and this one. For this study, information about those ideas has been obtained from work of Weigend Rodríguez et al. (2020) and reports from "Ellen Macarthur Foundation" (EMF) (EMF, 2012, 2015), and has been briefly described in this section.

The circular economy concept can be dated back to 1966, when Boulding (1966) explained the idea of "spaceman economy", comparing earth with a resource and pollution constraint spaceship, where humans have to live and meet their needs within a 'cyclical ecological system'. It is an example of circular economy, in contrast linear economy has been termed as "cowboy economy" i.e., considering the earth as endless plain with unlimited resources. In linear economy, resource consumption and production is considered as success, but in a resource constraint world, production and consumption should be lessened and the extent and quality of the capital stock (nature and human) should be a measure of success of economy (Boulding, 1966).

Another concept relevant to circular economy is 'performance economy' proposed by Stahel (1982), where emphasis has been given onto extending the product-life rather than replacing with another short lived product. It undertakes activities such as reuse, repair, reconditioning and recycling for product-life extension. This would largely reduce the extraction of resources and waste from used products (Stahel, 1982). In this system, the flow of products would be in a circle between the manufacturer and a consumer, and later would rather be called a user who utilises the services and pays for performance rather than for the product itself. Doing so, the service provider is obliged to provide quality service, and the product-life extension process is more labour-intensive work than resource intensive, which would lead to growth in jobs as well (Stahel, 2010).

The concept of 'Industrial Ecology' is also much related to circular economy. It was firstly proposed by Frosch and Gallopoulos (1989), which is about orientation of manufacturing systems as a biological ecosystem. As in a biological system, where there is a circular flow of nutrients from plants to animals and again back to plants, in industrial ecosystem, waste (by products) from manufacturing in one industry can be raw materials for other industry. Also in the production process, the energy and resources are optimised and waste are minimised in order to align with biological ways (Frosch and Gallopoulos, 1989). In addition to that, industrial ecology concept has also been used to compare the industrial economy to the ecosystem that supports it, in terms of the carrying capacity of the ecosystem. The deterioration technological society is causing to the ecosystem, for extraction of resources and sinks that has been used to dump those wastes (Reid and Thomas, 2002).

Another influence on circular economy is by the concept 'regenerative design', coined by Lyle (1994). It is about making our production process regenerative, i.e., the processes 
themselves would replace or renew the sources of energy and materials consumed (EMF, 2012; Weigend Rodríguez et al., 2020). Lyle suggested use of renewable energy sources, and keeping waste within the environment capacity, which would be restored back in environment without ecological damages (Weigend Rodríguez et al., 2020).

The next concept influencing circular economy is termed as 'Biomimicry,' which was defined by Benyus (2002) as a field of study about nature's ideas and to imitate nature's ideas in design and processes to solve our personal, societal, business and technological challenges. Biomimicry can be obtained through three principles, namely - nature as model (imitating nature's model), nature as measure (using nature as standard to measure sustainability), and nature as mentor (value nature on what it offers to learn from, not extract) (EMF, 2012).

Lovins et al. (1999) have proposed another concept which influences circular economy. They have termed it 'Natural Capitalism', which mentions that the economy itself is embedded in the natural environment and produces value from it. That makes the environment, natural capital the largest capital of our economy. So, current capitalistic economy should value the natural capital to generate sustainable benefits, both for present and future generations. The process as such can be performed by adapting four main practices in our economy; (1) manufacturing system should upgrade to reduce the consumption of resources in large scale, which in turn can produce more benefits than while consuming more resources and overcome the initial capital investment of the enterprise for upgrade, (2) manufacturing system should adapt the biological model where there is no waste generation, waste are either composted or reutilized as resources for another manufacturing unit, (3) business models should change from consuming to using model, where user pays for the leasing of services rather than buying of product, which ensures the flow of product and resources, (4) business should reinvest in restoring and expanding natural capital, which ultimately would be of some business value to the enterprise itself (Lovins et al., 1999).

Then there is 'cradle to cradle (C2C)' concept of zero waste with goal of attaining closed loop cycles of material flow. The cycles have to be regenerative and powered by renewable energies (McDonough et al., 2003). Other methods of improving efficiency of production being adapted, in one way or another depletes resources. In other hand, C2C design concept perceives 'biological metabolism' to develop a 'technical metabolism" process, and both processes are kept in mind, while designing products to maintain their value at different use cycles (EMF, 2012; Weigend Rodríguez et al., 2020). The main principles of $\mathrm{C} 2 \mathrm{C}$; (1) Waste equals food of imitating biological metabolism concept (2) Use current solar income of adapting 100\% renewable energy sources (3) Celebrate diversity of adapting to local ecology for setting out niche production systems, encapsulates many past ideas of ecology promoting economic ideas (McDonough et al. 2003). The aim of C2C concept is a step ahead of others as it aims to develop a system, where production processes have positive effect on ecology health and abundance (Braungart et al., 2007).

Finally, the newest significant influence to CE is by concept of 'Blue Economy' by Pauli (2010). This concept is based on principle of open-source movement, where various innovative business models, mainly small-scale businesses best suited to the local system and production would be adapted. and economy would be sustained in that locality. Such economic practices will also focus on enhancing well-being through mindful living, in 
harmony with nature (Pauli, 2010). The concept is a challenge to current economic model of continuous growth and promotes the integration of various known processes for utilising resources in a cascading system, to optimise use and minimise waste to the extent possible (Pauli, 2011; Weigend Rodríguez et al., 2020).

The current discourse on circular economy is led by 'Ellen Macarthur Foundation' (EMF), and defines it as a system, where the production process is 'restorative or regenerative by design' (see Figure 1). For that $\mathrm{C} 2 \mathrm{C}$ would determine the technical and biological cycles and aim to keep products, components, and materials at their highest utility and value at every use cycle (EMF, 2015). The EMF's ideas for CE principles are comprehensive and is influenced by most of the ideas discussed earlier. Based on different ideas EMF has developed three principles and an outline for circular economy, which has been taken from EMF report of 2015. The three main principles include; (1) Utilise only renewable energy sources, if not possible then use efficient technologies, dematerialise utility when possible, consume as less natural stocks as possible, instead enhance natural capital by encouraging flow of nutrients in biological system, (2) Design products for circularity i.e. reuse, remanufacturing, refurbishing, cascading and recycling to keep materials flow in circular loop, maintaining their highest utility at all times, either through biological and technical cycles, (3) Work to reduce the damaging impacts of production system through designing out the negative externalities. EMF has also suggested a framework for attaining circular economy termed as "ReSOLVE". The framework is generalisation of various working strategies into six one-word actions- regenerate, share, optimise, loop, virtualise and exchange; most of which has been already discussed previously in other concepts influencing CE.

The main objective behind all these concepts is about attaining sustainability in our development activities and same is applied for construction. Moreover, construction being a significant sector in terms of resource and energy consumptions, working to achieve circular economy in construction industry is vital for executing sustainable construction projects.

The sustainable construction practices till now have largely been associated to energy use and energy efficiency. The focus is on constructing sustainable buildings, but the circular economy (CE) concept suggests us to attain circularity in buildings i.e. circular buildings (Leising et al., 2018). Many other researches also have focused on recycling of construction and demolition waste without much attention to other aspects of CE such as design and reuse (Adams et al., 2017). CE approach for circularity in buildings considers whole of life cycle during design phase and seeks to adapt different ownership models for building materials, where building act as a material bank (Lacy, 2015). Circular buildings have also been simply defined as designed, planned built, operated, maintained, and deconstructed in manner consistent with CE principles (Pomponi and Moncaster, 2017). Report by ARUP in 2016 suggests adapting "Resolve" framework by Ellen Macarthur Foundation for adapting circular economy in construction. It suggests considering 7S model of building layers, which includes layers namely system, site, structure, skin, services, space and stuff, and decide our strategies for each layer to have a clear techniques of attaining circularity (Zimmann et al., 2016). 


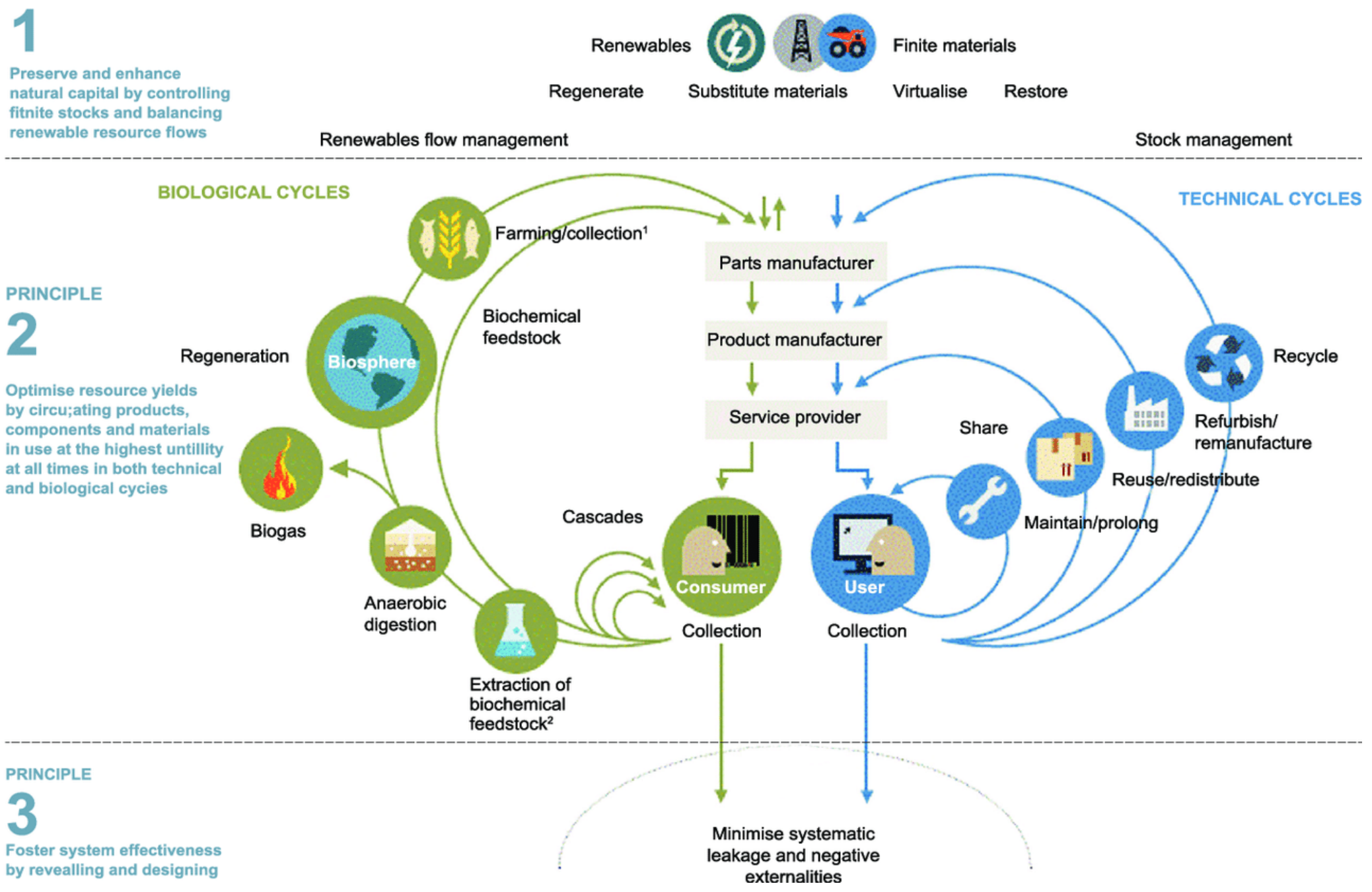

Figure 1: Principles and outline of circular economy (Source: EMF, 2015) 
In order to integrate life cycle analysis and material flow, the materials and resources flowing throughout the lifecycle of the building should be considered, i.e., whole of life cycle supply chain (Leising et al., 2018). For flow materials in such supply chain, it is necessary that all the stakeholders belonging to the stages of lifecycle; such as business owners, service providers, designers, contractors, demolition companies' users, government agencies, etc. would have to collaborate (Hossain et al., 2020; Leising et al., 2018; Zimmann et al., 2016). Such collaboration is required to develop a common platform for identification of possible business partners, information sharing and developing business models for sharing or flow of materials (Górecki et al., 2019; Hossain et al., 2020). The whole of built environment comprising of various businesses can act as industrial symbiosis network for supply chain collaboration (Herczeg et al., 2018), which is discussed from stakeholder management perspective next.

\section{STAKEHOLDER COLLABORATION FOR CIRCULAR BUILDING}

As the importance of collaboration has been realised, it makes sense that for a project of constructing circular building to be successful by attaining circularity, the supply chain actors would be important stakeholders and a project organisation must collaborate with such stakeholders to achieve project's objectives. This section starts with the discussions around basic concepts and techniques of stakeholder management in construction, followed by application of those techniques to prove the relevancy of stakeholder collaboration as an integral part of stakeholder management in circular building project.

\subsection{Stakeholder Collaboration in CONSTRUCTION}

Stakeholders for any project are people, community and organisations, who affect or are affected by project activities, and are required to be managed to prevent from impacting project performance. Different stakeholders have their different interests, and level of impact one stakeholder can cause is different than of others, thus requires different responses from project organisation (Chinyio and Olomolaiye, 2010). Newcombe (2003) suggests similar range for stakeholders, comprising of parties not just involved in project activities, but also parties, who have investment or interest in organisation. For a construction project, list of stakeholders might include the ones working in the project, financers, end users, general public, government agencies, media and so on (Chinyio and Olomolaiye, 2010). Different ways of classifying stakeholders have been proposed by different authors. Classifying into direct and indirect stakeholders is one of them (Project Management Institute, 2016; Smith and Love, 2004). Direct stakeholders have been described as those directly involved in the execution of the project, whereas indirect stakeholders are not directly involved, but influence execution of the project. This approach basically categorises project sponsors, project team and suppliers as direct stakeholders, whereas general public, governmental and non-governmental agencies, media etc. fall under indirect stakeholder category. The needs and requirements of direct project stakeholders will often be detailed in the contract documents, mainly specifications of the construction project (Project Management Institute, 2016). The stakeholders might also be classified as external and internal stakeholders, where internal type corresponds to the direct ones and external corresponds to indirect stakeholders discussed earlier (Atkin and Skitmore, 2008). There are other classification categories, which are also more or less similar to the ones discussed earlier in the paragraph. 
Stakeholders are required to be managed to minimise negative impacts they can cause and ensure that they do not obstruct achieving project goals. It is also required that the organisation keep good terms with stakeholders, who are constituent for project completion and maintain support of these parties by balancing their interests, as the impacts from stakeholders are both positive and negative (Chinyio and Olomolaiye, 2010). Stakeholder management in most of the construction projects seem to adapt processes, which are generally similar. The process includes identification of stakeholders; gathering information about stakeholders; assessing the information to determine interests, level of influence, urgency of stakeholders; determining priority for stakeholders through power/interest matrix (Newcombe, 2003) and determine strategies through cooperative/threatening matrix (Savage et al., 1991); decide the actions required to manage each stakeholder; and finally take actions based on the decisions made (Yang and Shen, 2015). Determining priority helps to guide actions on what degree of importance one stakeholder should be given, and to what level their interests be fulfilled (Newcombe, 2003). In addition to that, Savage et al. (1991) suggest a matrix to set strategies for stakeholder management based on the level of cooperative or threatening, stakeholders could be towards the organisation or its goals (see Figure 2).

Potential for Threat to organization/goals

\begin{tabular}{|c|c|c|c|}
\hline \multirow{3}{*}{$\begin{array}{c}\text { Potential for } \\
\text { cooperation with } \\
\text { organization/goals }\end{array}$} & & High & Low \\
\hline & High & $\begin{array}{c}\text { Stakeholder Type: } \\
\text { MIXED BLESSING } \\
\text { Strategy: } \\
\text { COLLABORATE }\end{array}$ & $\begin{array}{c}\text { Stakeholder Type: } \\
\text { SUPPORTIVE } \\
\text { Strategy: } \\
\text { INCLUDE }\end{array}$ \\
\hline & Low & $\begin{array}{c}\text { Stakeholder Type: } \\
\text { NONSUPPORTIVE } \\
\text { Strategy: } \\
\text { DEFEND }\end{array}$ & $\begin{array}{c}\text { Stakeholder Type: } \\
\text { MARGINAL } \\
\text { Strategy: } \\
\text { MONITOR }\end{array}$ \\
\hline
\end{tabular}

Figure 2: Stakeholder matrix for different strategies

Based on the matrix an organisation would be able to determine its strategy of collaborate, involve, defend and monitor depending upon the stakeholder type of mixed blessing, supportive, non-supportive and marginal, respectively to above mentioned strategies. This matrix is much relatable to a circular building project scenario and thus would be further discussed in context of such projects in following sub-section.

\subsection{Stakeholder COLlaboration FOR CirCUlar BUILDing}

Any construction projects for circular buildings, would set its prime goal as attaining circularity and support transition into circular economy. As per discussion so far, it has become almost obvious that every such project would have certain suppliers of materials and buyers of surplus in another construction or demolition project, in addition to the new material manufacturers. Along with such parties, experts for sustainability and circularity hired by either owner or contractor would also be stakeholder for circular building project. 
Stakeholder management in these projects would have to be done with emphasis on circularity goals along with the other conventional project objectives. The steps as described under previous heading of stakeholder management would be followed where stakeholders are identified, prioritised, strategies are developed, and actions are taken (Yang and Shen, 2015). While developing strategies through cooperate-threaten stakeholder matrix for a circular building project, and comparing with project scenario, end users of buildings, materials suppliers and circularity experts can be categorised as "mixed blessing" type stakeholders.

In context of current conceptual phase of $\mathrm{CE}$, materials manufacturers might have various clients and would be supplying materials to various other conventional projects making a sound profit. In order to manufacture reusable construction materials, it is important that share ideas and their technology to manufacture niche items, and while doing that also ensure their profit during the process. Long term collaboration is also necessary to implement concept of material banks. Collaboration for long term growth should be prioritised against quick benefits of linear economy. If using old reusable materials, it is important that parties involved in deconstruction of source building are collaborated beforehand to have design inputs in current project, based on the materials available to reuse. Manufacturers and suppliers opting towards linearity is a negative impact to circularity objectives.

End users on the other hand might invest on linear building, mainly due to lack of awareness (and unwillingness) about long term benefits of life cycle cost of circular buildings and reluctance towards reusable products. So, they must be ensured about the financial benefits and quality of circular buildings through collaboration from the conceptual phase and providing them a feeling of satisfaction and ownership about the investment they would be making on the project.

In addition to flow of materials and promote awareness, collaborative working methods has been suggested for innovation in various fields, be that in general (Roberts and Bradley 1991), or specifically in construction (Xue et al., 2018). For designing a building to be built with materials obtained from deconstruction and design to easily disassemble in future, and create a unique product requires innovation. With limit in expertise in this area and lagging of communication or miscommunication between clients and designers would complicate the design process and output may not be as desired, which may not fulfil our circularity criteria or become might become difficult to execute the design at site. Both would hinder the project's circularity goals.

Furthermore, stakeholder collaboration has been argued as vital for multi-sector innovation, which comprises of changes in different aspects of technical, social, economic, political, behavioural and biophysical environments (Bunn Michele et al., 2002). Implementing circular economy also demands changes in practices in different branches of construction industry. From change in design techniques, to way services are utilised and conduct business would be changed while transitioning to circular economy and will require collaboration with different organisational stakeholders and stakeholders within the project organisation as well. Thus, for a circular building project, stakeholder collaboration becomes integral part of stakeholder management. Collaboration would be necessary in both vertical project organisation and horizontal supply chain of materials. The key ideas discussed in above section with the stakeholders are depicted in Figure 3. 


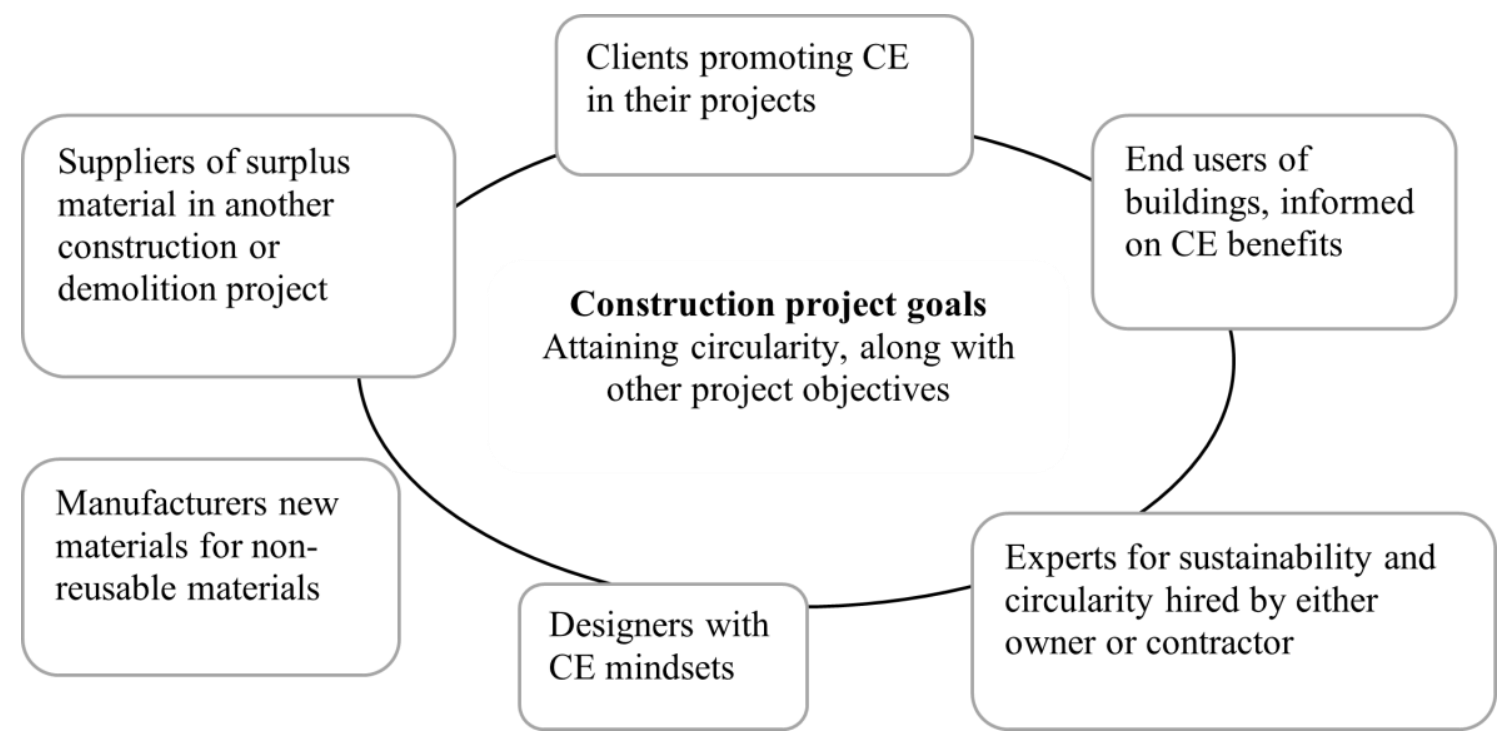

Figure 3: Importance of stakeholder collaboration for circular buildings

Blockchain is a disruptive technology that has attracted significant interest in several industries including construction industry in recent times. Blockchain comprises of a decentralised distributed ledger, which could be shared between all participants in a trusted environment without the need for a third party. It offers transaction traceability, transparency, and security, together with verification and validation processes on recording transactions. Blockchain is seen as a potential platform to connect all construction project stakeholders to achieve circular buildings and close the loop.

\section{CONCLUSIONS AND WAY FORWARD WITH BLOCKCHAIN TECHNOLOGY}

As circular economy is a promising solution to current scenario of resource and energy depletion and extreme carbon emissions, it can be a way to attain sustainable development and leave a better future for coming generations. So, transitioning into such system could be one of the top sustainability objectives. Construction sector being significant consumer of resources and energy, is a major player of this transition.

The circular economy practices in any sector is currently in initial stages. The undergoing works mainly focuses on transitioning from linear to circular economy The key findings from the current paper are establishing importance of stakeholder collaborations to achieve circular buildings. Such collaboration is required to develop a common platform for identification of possible business partners, information sharing and developing business models for sharing or flow of materials. In terms of material flows, need to track the reuse of materials, keep record of sources of materials and smooth transfer of material ownerships are also insisting on a common platform for large scale value chain actors' collaboration. Potential for blockchain technology to create such circular economy in construction will be explored in the next phase of this research.

\section{REFERENCES}

Adams, K.T., Osmani, M., Thorpe, T. and Thornback, J., 2017. Circular economy in construction: Current awareness, challenges and enablers. Waste and Resource Management, 170(1), pp. 15-24. 
Atkin, B. and Skitmore, M., 2008. Editorial: Stakeholder management in construction. Construction Management and Economics, 26(6), pp. 549-52.

Benyus, J.M., 2002. Biomimicry: Innovation Inspired by Nature. New York: Harper Perennial.

Bocken, N.M.P., de Pauw, I., Bakker, C. and van der Grinten, B., 2016. Product design and business model strategies for a circular economy. Journal of Industrial and Production Engineering, 33(5), pp. 308320.

Boulding, K.E., 1966. The economics of the coming spaceship earth in environmental quality in a growing economy. Essays from the Sixth RFF Forum, 3, pp. 1-20.

Braungart, M., McDonough, W. and Bollinger, A., 2007. Cradle-to-cradle design: Creating healthy emissions - A strategy for eco-effective product and system design. Journal of Cleaner Production, 15(13), pp. 1337-1348.

Bunn Michele, D., Savage Grant, T. and Holloway Betsy, B., 2002. Stakeholder analysis for multi-sector innovations, Journal of Business and Industrial Marketing, 17(2/3), pp. 181-203.

Chinyio, E. and Olomolaiye, P.O., 2010. Construction stakeholder management. Oxford: Wiley-Blackwell.

EMF., 2012. Towards the circular economy - economic and business rationale for an accelerated transition. UK: Ellen MacArthur Foundation. [Online] Available from: https://www.ellenmacarthurfoundation.org/assets/downloads/publications/Ellen-MacArthurFoundation-Towards-the-Circular-Economy-vol.1.pdf.

EMF., 2014. Towards the circular economy - accelerating the scale-up across global supply chains. UK: Ellen MacArthur Foundation. [Online] Available from:

https://www.ellenmacarthurfoundation.org/assets/downloads/publications/Towards-the-circulareconomy-volume-3.pdf.

EMF., 2015. Towards a circular economy: business rationale for an accelerated transition. UK: Ellen MacArthur Foundation. [Online] Available from: https://www.ellenmacarthurfoundation.org/assets/downloads/TCE_Ellen-MacArthur-Foundation_9Dec-2015.pdf.

Frosch, R.A. and Gallopoulos, N.E., 1989. Strategies for manufacturing. Scientific American, 261(3), pp. 144-152.

Górecki, J., Núñez-Cacho, P., Corpas-Iglesias, F.A. and Molina, V., 2019. How to convince players in construction market? Strategies for effective implementation of circular economy in construction sector. Cogent engineering, 6(1).

Herczeg, G. Akkerman, R. and Hauschild, M.Z., 2018. Supply chain collaboration in industrial symbiosis networks, Journal of Cleaner Production, 171, pp. 1058-1067.

Hossain, M.U., Ng, S.T., Antwi-Afari, P. and Amor, B., 2020. Circular economy and the construction industry: existing trends, challenges and prospective framework for sustainable construction. Renewable and Sustainable Energy Reviews, 130, p.109948.

Lacy, P., 2015. Waste to wealth: The circular economy advantage. New York: Palgrave Macmillan.

Leising, E., Quist, J. and Bocken, N., 2018. Circular economy in the building sector: Three cases and a collaboration tool, Journal of Cleaner Production, 176, pp. 976-989.

Lovins, A.B., Lovins, L.H. and Hawken, P., 1999. A road map for natural capitalism, Harvard Business Review, 77(3), pp. 145-158.

Lyle, J.T., 1994. Regenerative design for sustainable development, New York: John Wiley.

McDonough, W., Braungart, M., Anastas, P.T. and Zimmerman, J.B., 2003. Applying the principles of green engineering to cradle-to-cradle design, Environmental Science and Technology, 37(23), p. 434A.

Munaro, M.R., Tavares, S.F. and Bragança, L., 2020. Towards circular and more sustainable buildings: A systematic literature review on the circular economy in the built environment. Journal of Cleaner Production, 260, pp. 121-134.

Newcombe, R., 2003. From client to project stakeholders: A stakeholder mapping approach, Construction Management and Economics, 21(8), pp. 841-848.

Pauli, G., 2010. The Blue Economy. [Online] Available from: https://www.theblueeconomy.org/.

Pauli, G., 2011. The Blue Economy. Japan Spotlight: Economy, Culture and History, 30(1), p. 14. 
Pomponi, F. and Moncaster, A., 2017. Circular economy for the built environment: A research framework. Journal of Cleaner Production, 143, pp. 710-718.

Project Management Institute, 2016. Construction extension to the PMBOK® guide, Newtown Square, Pennsylvania: Project Management Institute, Inc.

Reid, L. and Thomas, E.G., 2002. Industrial ecology: Goals and definition. Edward Elgar Publishing.

Roberts, N.C. and Bradley, R.T., 1991. Stakeholder collaboration and innovation: A study of public policy initiation at the state level. The Journal of Applied Behavioural Science, 27(2), pp. 209-227.

Savage, G.T., Nix, T.W., Whitehead, C.J. and Blair, J.D., 1991. Strategies for assessing and managing organizational stakeholders. The Executive, 5(2), p. 61.

Smith, J. and Love, P.E.D., 2004. Stakeholder management during project inception: Strategic needs analysis. Journal of Architectural Engineering, 10(1), pp. 22-33.

Stahel, W.R., 1982. The product life factor. An inquiry into the nature of sustainable societies: The role of the private sector. NARC.

Stahel, W.R., 2010. The performance economy. $2^{\text {nd }}$ ed. Basingstoke, England; New York

Weigend Rodríguez, R., Pomponi, F., Webster, K. and D'Amico, B., 2020. The future of the circular economy and the circular economy of the future. Built Environment Project and Asset Management, 10(4), pp. 529-546.

Xue, X., Zhang, X., Wang, L., Skitmore, M. and Wang, Q., 2018. Analyzing collaborative relationships among industrialized construction technology innovation organizations: A combined SNA and SEM approach. Journal of Cleaner Production, 173, pp. 265-277.

Yang, R.J. and Shen, G.Q.P. 2015. Framework for stakeholder management in construction projects. Journal of Management in Engineering, 31(4), pp. 401-406.

Zimmann, R., O'Brien, H., Hargrave, J. and Marcus, M., 2016. The circular economy in the built environment. ARUP, London, UK. [Online] Available from:

https://www.arup.com/-/media/arup/files/publications/c/arup_circulareconomy_builtenvironment.pdf. 